\title{
Fever in pregnancy and its maternal and fetal outcome at tertiary care level
}

\section{Poovathi*, N. Prasanna}

Department of Obstetrics and Gynecology, KAPV Government Medical College, Trichy, Tamil Nadu, India

Received: 02 March 2018

Accepted: 28 March 2018

\section{*Correspondence:}

Dr. M. Poovathi,

E-mail: drmpoovathi@gmail.com

Copyright: (C) the author(s), publisher and licensee Medip Academy. This is an open-access article distributed under the terms of the Creative Commons Attribution Non-Commercial License, which permits unrestricted non-commercial use, distribution, and reproduction in any medium, provided the original work is properly cited.

\begin{abstract}
Background: The fever during pregnancy is the omnious sign. Early detection and prompt management of fever prevents maternal mortality and morbidity. Any maternal hyperthermia $\left(>38.9^{\circ} \mathrm{C}\right)$ potentially affect the fetus. Hence study was conducted to know the outcome of fever in pregnancy.

Methods: To study the outcome of pregnant women admitted with fever in obstetrics ward at MGMGH, Trichy over the period of 6 months from July 2017 to December 2017.

Results: The incidence of fever was $6 \%$. In this study the most common cause was viral fever among which dengue fever was most common. Hence outcome depends on its impact on pregnant mother and fetus. Many preterm labour $(24 \%)$ were noted in this study which needs NICU admission of babies. Maternal mortality was $25 \%$, most of it were associated with DIC, IUD and one or two combined risk factors.

Conclusions: The incidence of fever was $6 \%$. In this study the most common cause was viral fever among which dengue fever was most common. Hence outcome depends on its impact on pregnant mother and fetus. Many preterm labour $(24 \%)$ were noted in this study which needs NICU admission of babies. Maternal mortality was $25 \%$, most of it were associated with DIC, IUD and one or two combined risk factors.
\end{abstract}

Keywords: Fever, Preterm labour, Temperature

\section{INTRODUCTION}

The incidence of fever varies with time period. During six month of our study there was dengue outbreak in trichy. Hence this time period was selected to know the overall outcome of the fever in pregnancy.

The fever during pregnancy is the omnious sign. Early detection and prompt management of fever prevents maternal mortality and morbidity. Any maternal hyperthermia $\left(>38.9^{\circ} \mathrm{C}\right)$ potentially affect the fetus. ${ }^{1}$

Consequences of fever depends on the extent and duration of temperature elevation, timing of the exposure in pregnancy, and possibly on maternal nutritional status, comorbidities, medications, genetic background, and several other factors. The exposure of maternal temperature has been reported to lead to cell disruptions, vascular disruption and placental infarction, which affect the risk of structural and functional defect in the offspring. ${ }^{2}$

An episode of fever is of common occurrence in pregnancy.

A surveillance of the effect and to study the incidence of fever in pregnancy during study period, to know the etiology of fever in pregnancy, to know the etiology of fever in pregnancy. 


\section{METHODS}

This study was conducted at MGMGH Trichy for the duration of six months from july 2017 to December 2017. It is referral hospital covering large population in Trichy and also get referral cases from pudukottai,perambalur and karur. During this study dengue outbreak was there hence many cases presented with thrombocytopenia misleading in diagnosis of preeclampsia cases. For all admitted fever cases careful and detailed history taking, careful clinical examination, complete blood count including the platelet count, urine routine, USG abdomen and pelvis, widal, dengue serology, peripheral smear, blood culture and urine culture were done. ${ }^{3,4}$ The causes of fever was identified. The maternal and fetal outcome was noted.

\section{Management}

The bacterial infection was treated with i.v antibiotics and changed according to blood culture report. If patient presented with thrombocytopenia or dengue serology positive treated with i.v fluids to maintain hydration. Serial CBC monitoring till thrombocytopenia recovers. ${ }^{5}$ The patients were discharged only after getting the physician fitness. Mosquitoes nets were provided to the patients. Separate fever ward was opened inside the labour room for continues vitals monitoring of patient. Many thrombocytopenia cases were admitted during outbreak period. Concerned area were alerted for mosquitoes controlled by proper fogging. Paediatricians were alerted if preterm delivery was conducted. ${ }^{6,7}$ Anaesthetist were called for ICU care. Thus, team management help in treating the fever cases. ${ }^{8}$ The critically ill patient were monitored in ICU. The cause of fever was identified and treat accordingly. Associated pregnancy related conditions like GHT, GDM, PROM was identified treated carefully.

\section{RESULTS}

The total number of fever cases admitted during six months period was 357 cases. Out of 357 fever cases peak admission was noted during October month (134 fever admissions).

Table 1: Total number of fever cases admitted in the labour ward for six month duration.

\begin{tabular}{|l|l|}
\hline Month & Total no. of cases \\
\hline July & 11 \\
\hline August & 15 \\
\hline September & 49 \\
\hline October & 134 \\
\hline November & 83 \\
\hline December & 65 \\
\hline Total & 357 \\
\hline
\end{tabular}

Out of 357 fever cases total number of antenatal cases were 245, postnatal cases (102) including the fever in postnatal mother with fever who delivered in MGMGH and also referred from outside PHC. Among 357 antenatal cases 115 were delivered on admission.

Table 2: Distribution of fever cases in antenatal and postnatal mother.

\begin{tabular}{|ll|}
\hline Distribution & Total no of cases \\
\hline Antenatal mother & 245 \\
\hline Postnatal mother & 102 \\
\hline $\begin{array}{l}\text { Number of antenatal fever } \\
\text { cases who delivered }\end{array}$ & 115 \\
\hline
\end{tabular}

Table 3: Distribution of fever cases according to the cause.

\begin{tabular}{|ll|}
\hline Causes & Number of cases \\
\hline Upper respiratory infection & 44 \\
\hline Lower respiratory infection & 51 \\
\hline Typhoid & 11 \\
\hline Malaria & 5 \\
\hline Dengue & 49 \\
\hline Viral fever & 81 \\
\hline Scrub typhus & 2 \\
\hline Urinary tract infection & 41 \\
\hline Postoperative fever & 42 \\
\hline Hepatitis & 3 \\
\hline Wound infection & 6 \\
\hline Unknown pyrexia & 8 \\
\hline Chicken pox & 11 \\
\hline Tuberculosis & 3 \\
\hline
\end{tabular}

The fever cases were distributed according to the causes for fever. Among which Dengue serology positive cases (it includes both NS1 positive and IgM positive) were 49, the viral fever of unknown causes including the fever with thrombocytopenia cases were 81 (dengue serology negative mimics dengue fever). Two scrub typhus cases with eschar were noticed during study period. Due to chicken pox admitted cases were 11 . The postoperative fever cases that were shifted to labour ward was 42 cases.

Table 4: Distribution of antenatal cases according to gestational age.

\begin{tabular}{|l|l|}
\hline Gestational age & Numbers \\
\hline Less than 32 weeks & 81 \\
\hline 32 to 36 weeks & 82 \\
\hline 37 to 40 weeks & 71 \\
\hline$>40$ weeks & 11 \\
\hline Total & 245 \\
\hline
\end{tabular}

Among 245 antenatal fever cases 11 were admitted as prolonged pregnancy, 71 were between 37 to 40 weeks, 82 were between 32 to 36 weeks and remaining were less than 32 weeks gestational age.

Among 245 antenatal cases, PROM (11), anaemia (41), GHT (19), polyhydramnios (5), jaundice cases were 
associated with complication like preterm labour (28), (6), IUD (14) GDM (7), oligohydramnios (19), abruption (4). Fever associated with preterm labour, anaemia and IUD has greater impact on fetal and maternal outcome.

Table 5: Outcome of antenatal cases.

\begin{tabular}{|l|l|}
\hline Complications & Numbers \\
\hline Preterm Labour & 28 \\
\hline Oligohydramnios & 19 \\
\hline Hyperemesis gravidarum & 17 \\
\hline False labour pain & 30 \\
\hline GHT & 19 \\
\hline Abruption & 4 \\
\hline Polyhydramnios & 5 \\
\hline Fetal distress & 21 \\
\hline Anaemia & 41 \\
\hline PROM & 11 \\
\hline Jaundice & 6 \\
\hline GDM & 7 \\
\hline Seizure disorder & 4 \\
\hline IUD & 14 \\
\hline No comorbidities & 19 \\
\hline Total & 245 \\
\hline
\end{tabular}

Table 6: Mode of delivery in $\mathbf{1 1 5}$ antenatal cases.

\begin{tabular}{|ll|}
\hline Mode of delivery & Numbers \\
\hline FTNVD & 35 \\
\hline Preterm normal delivery & 28 \\
\hline LSCS & 31 \\
\hline Ectopic & 2 \\
\hline Abortion & 16 \\
\hline Outlet forceps & 3 \\
\hline Total & 115 \\
\hline
\end{tabular}

Among 115 antenatal cases delivered 35 were full term normal vaginal delivery (30\%), 28 preterm labour (24\%), LSCS-31 cases (26\%), two ruptured ectopic pregnancy, 16 cases in early gestation aborted (13\%) and three outlet forceps delivery. Out of which 48 babies were admitted in NICU. Among 14 IUD cases, 10 were referred from outside.

Table 7: Fetal outcome in delivered cases: (exclude ectopic and abortion).

\begin{tabular}{|ll|}
\hline Fetal outcome & No. \\
\hline Healthy baby with mother & 34 \\
\hline IUD & 14 \\
\hline NICU admission & \\
\hline Meconium stained & 11 \\
\hline IUGR & 9 \\
\hline LBW & 28 \\
\hline Total & 96 \\
\hline
\end{tabular}

Among 115 antenatal cases delivered 35 were full term normal vaginal delivery (30\%), 28 preterm labour $(24 \%)$, LSCS-31 cases (26\%), two ruptured ectopic pregnancy,16 cases in early gestation aborted (13\%) and three outlet forceps delivery. Out of which 48 babies were admitted in NICU. Among 14 IUD cases, 10 were referred from outside.

Table 8: Maternal outcome in fever cases.

\begin{tabular}{|ll|}
\hline Maternal outcome & Numbers \\
\hline Antenatal mother discharged & 237 \\
\hline Absconded & 9 \\
\hline Postnatal mother discharged & 100 \\
\hline Against medical advice & 4 \\
\hline Maternal mortality & 7 \\
\hline Total & 357 \\
\hline
\end{tabular}

In total 357 fever cases, 237 antenatal cases, 100 postnatal cases were discharged, 9 cases absconded and 4 cases were discharged against medical advice. The maternal mortality among fever cases was 7. Viral haemorrhagic fever associated with thrombocytopenia with DIC contribute to the leading factor for maternal mortality. Among seven maternal mortality cases five cases was IUD added contributing factor for fever, thrombocytopenia and DIC. All seven cases were referred from PHC. Thus early referral, prompt critical care and adequate fluid management prevent in maternal mortality.

\section{DISCUSSION}

In our six month study,total number of deliveries were 5168. The total number of fever cases admitted during six months period was 357 cases. Thus, the incidence of fever in our study was 6\%. Among which dengue serology positive cases were 49, the viral fever of unknown causes including the fever with thrombocytopenia cases were 81 .

Dengue fever is a mosquito borne virus infection. It is endemic world wide in tropic and subtropic countries. It is caused by a flavivirus spread by the vector mosquito Aedes aegypti. The maternal risks in dengue was deranged liver functions with thrombocytopenia mimics HELLP syndrome. It is associated with high maternal mortality unless treated promptly and aggressively. There is no teratogenic effect on fetus. But in term period intrauterine death of fetus, still birth can occur. Evidence of vertical mother to fetal transmission present it results in thrombocytopenia, fever and hepatomegaly in the newborn babies. The diagnosis is made on investigations to rule out clinical pictures are leukopenia, haeoconcentration, thrombocytopenia, elevated liver enzymes, ELIZA TEST, IgM ELISA, NS1 positive. ${ }^{9}$ The regular $\mathrm{CBC}$ monitoring and look warning signs like abdominal pain, sever head ache, vomiting. The main pathogenesis was capillary leakage. The adequate fluid management is essential and main mode of treatment. ${ }^{10}$

Two scrub typhus cases with eschar were noticed during study period. Due to chicken pox admitted cases were 11 . 
The postoperative fever cases that were shifted to labour ward was 42 cases. The srub typhus fever was caused by Scrub typhus. It is a form of intracellular parasite Orientia tsutsugamushi, a Gram-negative $\alpha$ proteobacterium of family Rickettsiaceae. ${ }^{11}$

Signs and symptoms include fever, headache, muscle pain, cough, and gastrointestinal symptoms. The most virulent strains of $O$. Tsutsugamushi can cause hemorrhage and intravascular coagulation. Morbilliform rash, eschar, splenomegaly, and lymphadenopathies are typical signs. Leukopenia and abnormal liver function tests are commonly seen in the early phase of the illness. Pneumonitis, encephalitis, and myocarditis occur in the late phase of illness. Without treatment, the disease is often fatal. Since the use of antibiotics, case fatalities have decreased from $4-40 \%$ to less than $2 \%$.

The drug of choice was doxycycline or tetracycline. But in pregnant women with scrub typhus azithromycin is alternative drug of choice. ${ }^{12,13}$ The other cause of fever like upper respiratory infection, chicken pox, malaria, typhoid also contribute to cause of fever in our study.

Among 245 antenatal cases, PROM (11), anaemia (41), GHT (19), polyhydramnios (5), jaundice cases were associated with complication like preterm labour (28), (6), IUD (14) GDM (7), oligohydramnios (19), abruption (4). Fever associated with preterm labour,anaemia and IUD has greater impact on fetal and maternal outcome. Already most of the fever cases with altered coagulation failure added high risk factor like anaemia, IUD. The incidence of preterm labour around $24 \%$ it contributes to increase in NICU admission. Thus, it increase the risk of neonatal mortality and morbidity. Carles $\mathrm{G}$ et al found that the rate of fetal death associated with dengue fever was $13.6 \%$. In our study it contributes to $12 \%$ (IUD).

The maternal mortality in our study was $25 \%$ which was very high. Among seven maternal mortality cases five cases was IUD added contributing factor with fever, thrombocytopenia and DIC. All seven cases were referred from PHC. Thus, early referral, prompt critical care and adequate fluid management prevent in maternal mortality.

\section{CONCLUSION}

The most common cause of fever is viral fever among which dengue haemorrhagic fever was the most common cause. The peak period of fever was October month. The incidence of fever in present study for six months period is $6 \%$. The maternal mortality associated with fever was high $(25 \%)$ during fever outbreak. Thus, preventive measures and early referral from primary health centre help in preventing maternal mortality and neonatal mortality. In dengue fever outbreak, adequate fluid management is essential where as in case of bacterial infection proper antibiotic coverage was important.

Funding: No funding sources

Conflict of interest: None declared

Ethical approval: The study was approved by the Institutional Ethics Committee

\section{REFERENCES}

1. Edwards MJ, Saunders RD, Shiota K. Effect of heat on embryos and fetuses. Int $\mathbf{J}$ Hyperthermia. 2003;19(3):295-324.

2. Chamber CD, Johnson KA, Dick LM, Felix RJ, Jones KL. Maternal fever and birth outcome: a prospective study. Teratol. 1998;58:251-7.

3. Saba N, Sultana A, Mahsud I. Outcome and complication of malaria in pregnancy. Gomal J Med Sci. 2008;6(2):98-101.

4. Gary FC. William's Obstetrics. $23^{\text {rd }}$ ed. New York: McGraw-Hill, Medical; 2010:804-831.

5. Basurko C, Carles G, Youssef M, Guindi WE. Maternal and fetal consequence of dengue fever during pregnancy. Eur J Obstet Gynaecol Reprod Biol. 2009;147(1);29-32.

6. Cloherty JP. Manual of Neonatal Care. 2011:74-90.

7. American College of Obstetricians and Gynecologists. 2003. Management of preterm labor. ACOG Practice Bulletin No. 43. Obstet Gynecol 101:1039-47.

8. Arias F. Practical Guide to High-Risk Pregnancy and Delivery. 2008:193-216.

9. Charles G, Peiffer H, Talarmin A. Effect of dengue fever during pregnancy in French Guiana. Clin Infect Dis. 1999;28(3):637-40.

10. Basurko C, Carles G, Youssef M, Guindi WE. Maternal and fetal consequence of dengue fever during pregnancy. Eur J Obstet Gynaecol Reprod Biol. 2009;147(1):29-32.

11. Tseng BY, Yang HH, Liou JH, Chen LK, Hsu YH. Immunohistochemical study of scrub typhus: a report of two cases. Kaohsiung J. Med. Sci. 2008;24(2).

12. Choi EK, Pai H. Azithromycin therapy for scrub typhus during pregnancy. Clin Infect Dis. 1998;27(6):1538-9.

13. Watt G, Kantipong P, Jongsakul K, Watcharapichat P, Phulsuksombati D. Azithromycin activities against Orientia tsutsugamushi strains isolated in cases of scrub typhus in Northern Thailand. Antimicrob Agents Chemother. 1999 Nov;43(11):2817-8.

Cite this article as: Poovathi M, Prasanna N. Fever in pregnancy and its maternal and fetal outcome at tertiary care level. Int J Reprod Contracept Obstet Gynecol 2018;7:1864-7. 